\title{
FeS Encapsulated Chitosan Graft Polyacrylamide Nanocomposite for the Uptake of Model Anionic Eosin Y from Water: Isotherm, Kinetics and Equilibrium Studies.
}

\section{Bernice Y. Danu}

Kwame Nkrumah University of Science and Technology College of Science

Eric S. Agorku ( $\sim$ seaky2k@gmail.com )

Kwame Nkrumah University of Science and Technology College of Science https://orcid.org/00000003-4198-554X

\section{Francis K. Ampong}

Kwame Nkrumah University of Science and Technology College of Science Johannes A.M. Awudza

Kwame Nkrumah University of Science and Technology College of Science

\section{Vincent Torve}

Kwame Nkrumah University of Science and Technology College of Science

\section{Caleb Amponsah}

Kwame Nkrumah University of Science and Technology College of Science

\section{Ruth N.M Quaye}

Kwame Nkrumah University of Science and Technology College of Science

\section{Onoyivwe M. Ama}

Vaal University of Technology

\section{Peter 0. Osifo}

Vaal University of Technology

\section{Suprakas S. Ray}

University of Johannesburg - Doornfontein Campus

\section{Research}

Keywords: Grafting, Chitosan-g-acrylamide, Iron sulphide, pseudo-second-order kinetics, Freundlich isotherm

Posted Date: June 2nd, 2020 
License: (c) (i) This work is licensed under a Creative Commons Attribution 4.0 International License. Read Full License

Loading [MathJax]/jax/output/CommonHTML/jax.js 


\section{Abstract}

A novel bio-nanocomposite, FeS encapsulated chitosan grafted polyacrylamide, was successfully synthesized using a grafting technique that employs microwave irradiation. Employing FTIR, SEM, XRD, TEM and SAED analysis, the synthesized nanocomposites were characterized. Thermodynamic and kinetic studies were accomplished using the batch mode via the eosin yellow adsorption from aqueous solution using the nanocomposite. The adsorption process was tailored to the pseudo-second-order kinetic model and the Freundlich isotherm model. The enthalpy change, $\Delta H^{\circ}(-12.243 \mathrm{~kJ} / \mathrm{mol})$, was an exothermic process. The Gibbs energy, $\Delta \mathrm{G}^{\circ}$ (from $-5.492 \mathrm{~kJ} / \mathrm{mol} . \mathrm{K}$ to $-5.078 \mathrm{~kJ} / \mathrm{mol}$.K for temperatures from $300 \mathrm{~K}$ to $318 \mathrm{~K}$ respectively) values were indications of a thermodynamically feasible reaction process which was spontaneous within the temperature domain. The change in entropy, $\Delta S^{\circ}(-0.023$ $\mathrm{kJ} / \mathrm{mol}$ ), showed reduced randomness during the adsorption process. The mean free energy of adsorption was $0.408 \mathrm{~kJ} / \mathrm{mol}$, which was an indication of physisorption. These results show the possible use of the graft copolymer as an adsorbent in water treatment.

\section{Introduction}

Water pollution due to the discharge of effluents from industries is of critical concern owing to its hazardous nature and threat it poses to humans and the environment. A major industry that contributes to the release of these effluents is the textile and dyeing industry. Textile and dyeing industries utilize a generous amount of water during manufacturing and employ toxic colorants such as dyes in the colouring of their final products. Consequently, they are considered one of the largest generators of contaminated wastewater [1-5]. Owing to the complexities of the aromatic structure of most dyes, it is an arduous task to remedy these pollutants since they are stable to light and heat and non- biodegradable [6]. Various remediation techniques which include chemical oxidation, electrocoagulation, coagulation, anaerobic and aerobic microbial degradation, membrane separation and adsorption have been explored extensively for the uptake of dyes from contaminated effluents [7, 8]. Conversely, adsorption has demonstrated to be a good and efficient means of treating dye effluents, because it gives off highly treated effluents. Several suitable low-cost adsorbents, namely peat, silica, bentonite, fly ash, wood shavings and maize cob [9] have been employed in wastewater treatments but these adsorbents generally have low removal rate thus large magnitudes are needed for the complete treatment of dye effluents [6]. Recently, attention has been concentrated on biomaterials for dye removal owing to their advantage over synthetic polymers. These biomaterials are biodegradable, low cost and easily available [10]. Another advantage is that they do not leave residues of the by-products and can easily be isolated after the adsorption process is completed [10-12]. Despite these advantages, biopolymer-based adsorbents have poor mechanical strength and water solubility as compared to synthetic polymers. It is, therefore, necessary to improve their strength and stability by modifying its properties by graft copolymerization and the incorporation of nanoparticles $[13,14]$. Nanoparticle-based adsorbents have drawn significant attention because of unique properties such as very small size and high surface area to volume ratio $[15,16]$. Integration of these nanoparticles inside the polymer matrix not only grows the 
surface area but also provides additional properties for the attachment of dye molecules [17]. Graft copolymerization is the method in which one or more polymers are covalently bonded to the polymer backbone of another polymer [18].

Chitosan is known to be a bio-compatible, biodegradable, bio-inexhaustible, non-toxic polymer and the second most bounteous regular polysaccharide after cellulose known to mankind. It is obtained from the deacetylation of chitin which takes place in the exoskeleton of insects, crustacean shells, shrimps, prawns as well as the cell walls of fungi $[19,20]$. Due to its amine and hydroxyl functional groups, it can attract the alkyl, acetyl, sulphonyl and carboxylic groups in dyes [21]. Acrylamide is a receptive composite utilized as a monomer for the amalgamation of polyacrylamide. Owing to its elevated-water retaining capacity, it has been utilized in wastewater treatment and drug delivery [22].

In this work, chitosan was modified by microwave-assisted grafting of polyacrylamide followed by the dispersion of FeS nanoparticles for the adsorption of Eosin yellow from aqueous solutions. Experimental adsorption isotherms, kinetics data, and thermodynamic properties were analysed using different adsorption models.

\section{Materials And Methods}

All chemicals used were of analytical grade and used without further treatment. Glycerol, $\mathrm{FeSO}_{4} \cdot 7 \mathrm{H}_{2} \mathrm{O}$, $\mathrm{Na}_{2} \mathrm{~S}$, ethanol, eosin yellow (EY), chitosan, acrylamide, and acetic acid were obtained from Sigma Aldrich, Germany.

\subsection{Synthesis of FeS nanoparticle}

Hundred $(100) \mathrm{ml}$ of aqueous $0.5 \mathrm{M}$ of $\mathrm{FeSO}_{4} \cdot 7 \mathrm{H}_{2} \mathrm{O}$ and $2 \mathrm{ml}$ of glycerol were added together with vigorous stirring under $\mathrm{N}_{2}$ gas atmosphere. $100 \mathrm{ml}$ of $\mathrm{Na}_{2} \mathrm{~S}$ aqueous solution under continuous stirring was added dropwise to the mixture until a colour change was observed from pale green to brick brown and finally to dark green. This was stirred for about 20 minutes and washed with deionized water and ethanol repeatedly. The final product was then dried in a hot air oven at $333 \mathrm{~K}$ overnight. Dried FeS was powdered and stored for further application.

\subsection{Fabrication of FeS/chitosan graft poly(acrylamide) nanocomposite}

Two (2) g of chitosan was dissolved in $100 \mathrm{ml} 1 \%$ acetic acid and added dropwise to $50 \mathrm{ml}$ acrylamide $(0.1 \mathrm{M})$ solution with continuous stirring. An appropriate amount of FeS was added into the reaction mixture while stirring for about 45 minutes. The resulting mixture was set in a microwave reactor at $333 \mathrm{~K}$ for a period of 15-20 minutes at 15 psi pressure [22]. The product was washed copiously with deionized 
water to take out any homopolymer that is created during the reaction. The final product was dried at $333 \mathrm{~K}$ in a hot air oven overnight, after which it was ground to powder and stored for future application.

\subsection{Batch Experiments}

Eosin yellow stock solution was prepared by dissolving $0.3 \mathrm{~g}$ in $1 \mathrm{~L}$ of deionized water. Using serial dilution, successive solutions required for the working solution were produced from the stock solution.

\subsubsection{Adsorption Conditions}

Using batch adsorption experiments, various parameters were determined by agitating a desired amount of the composite with the dye solutions $(50 \mathrm{ml})$ of preferred $\mathrm{pH}$ and concentration on a mechanical shaker at $150 \mathrm{rpm}$ agitation speed. The effect of contact time was varied between 10 to 90 minutes. For the effect of loading (adsorbent dose), 0.05 to $0.40 \mathrm{~g}$ of FeS/chitosan-g-poly(acrylamide) nanocomposite was agitated with $50 \mathrm{ml}$ EY solution at constant concentration and temperature for 2 hours. Five (5) initial concentrations for EY ranging from 60 to $150 \mathrm{mg} / \mathrm{L}$ were utilized for studying the impact of EY concentration onto FeS/chitosan-g- poly(acrylamide) composite at $300 \mathrm{~K}$. The influence of $\mathrm{pH}$ was varied between 2 to 10 using $0.1 \mathrm{M} \mathrm{NaOH}$ and $0.1 \mathrm{M} \mathrm{HCl}$ solutions. The impact of temperature was analyzed at several temperatures $(300,303,308,313$, and $318 \mathrm{~K})$ using $50 \mathrm{ml}\left(100 \mathrm{mg} \mathrm{L}^{-1}\right) \mathrm{EY}$ solutions in a MaxQ 8000 incubator stackable shaker. The residual EY concentrations in aqueous solutions were measured using a Shimadzu (UVmini-1240) UV-Vis spectrophotometer at an absorbance of $516 \mathrm{~nm}$.

\subsection{Theory}

\subsubsection{Removal Efficiency and Adsorption Capacity}

The amount of dye adsorbed, Qe or R.E were computed as follows:

$$
\text { R. } E=\frac{C_{o-C_{f}}}{C_{o}} \times 100
$$

where, $C_{o}$ is initial EY concentration $\left(\mathrm{mg} \mathrm{L}^{-1}\right), C_{f}$ is final EY concentration $\left(\mathrm{mg} \mathrm{L}^{-1}\right)$

and,

$$
Q_{e}=\frac{C_{o-C_{f}}}{M} \times V
$$


where, $C_{o}$ is initial EY concentration $\left(\mathrm{mg} \mathrm{L}^{-1}\right), C_{f}$ is final EY concentration $\left(\mathrm{mg} \mathrm{L}^{-1}\right), M$ is mass of FeS/Chitosan-g-polyacrylamide (g)

$V=$ volume of the $\mathrm{EY}$ solution $(\mathrm{L})$

\subsubsection{Adsorption Isotherms}

Adsorption isotherms portray the behaviour of the interaction between the adsorbent and the adsorbate molecules at equilibrium. The data obtained was tested using the Langmuir, Freundlich and DubininRadushkevich adsorption isotherm models. These isotherm models can be used to illustrate the equilibrium characteristics of adsorption.

The Langmuir isotherm assumes that there is a homogeneous dispersion of active adsorption sites on the adsorbent surface which absorbs a single layer adsorbate molecule with no interaction between the adsorbed molecules. The Langmuir isotherm equation is described by the equation [23];

$$
Q_{e}=\frac{Q_{m K_{L} C_{e}}}{1+K_{L} C_{e}}
$$

3

where $C_{e}\left(\mathrm{mg} \mathrm{L}^{-1}\right)$ is the liquid phase concentration at equilibrium and $Q_{e}\left(\mathrm{mg} \mathrm{g}^{-1}\right)$ is the mass of the dye concentration absorbed per unit mass. A graph of $1 /$ Qe versus $1 / C_{e}$ was plotted.

The Freundlich model assumes that with an increment in adsorbate concentration, the concentration of the adsorbate on the adsorbent surface also builds, corresponding to exponential decreases in adsorption energy after all the adsorption centers on the adsorbent are occupied. The expression for this model is [24];

$$
\log Q_{e}=\frac{1}{n} \log C_{e}+\log K_{F}
$$

4

where $Q_{e}$ is the quantity of EY uptake per unit mass $(\mathrm{mg} / \mathrm{g}), C_{e}$ is the equilibrium concentration of EY (mg $\left.\mathrm{L}^{-1}\right)$ and $K_{F}\left(\mathrm{mg} \mathrm{g}^{-1}\right)\left(\mathrm{L} \mathrm{mg}^{-1}\right)^{1 / \mathrm{n}}$ and $1 / n$ are constants denoting the adsorbent capacity and the heterogeneity factor, respectively. The value of $1 / n$ must be between zero and unity for favourable adsorption.

The Dubinin-Radushkevich isotherm describes whether the adsorption was physical or chemical. This is described by the equation [25-27];

Loading [MathJax]/jax/output/CommonHTML/jax.js $q_{e}=\ln q_{D R}-\beta \epsilon^{2}$ 
where $q_{m}\left(\mathrm{mg} \mathrm{g}^{-1}\right)$ is the Dubinin-Radushkevich maximum monolayer adsorption capacity, $\beta\left(\mathrm{mol}^{2} \mathrm{~J}^{-2}\right)$ is activity coefficient associated to mean adsorption energy, and $\varepsilon$ is the Polanyi potential which can be computed using the relationship

$$
\epsilon=R \ln \left(1+\frac{1}{C_{e}}\right)
$$

where $R\left(8.314 \mathrm{~J} \mathrm{~mol}^{-1} \mathrm{~K}\right)$ is the gas constant, $T(\mathrm{~K})$ is temperature and $C_{e}\left(\mathrm{mg} \mathrm{L}^{-1}\right)$ is the concentration of adsorbate at equilibrium.

\subsection{Characterization}

The morphology of the nanocomposite and the grafted copolymer were obtained using scanning electron microscope (SEM) and transmission electron microscope (TEM). Selective area electron diffraction (SAED) analysis was obtained from the TEM. X-ray diffraction (XRD) analysis was used for the identification of the crystal structure of the materials. Fourier transform infra-red spectroscopy (FTIR) was used to determine the functional groups and the chemical bonds present in the materials.

\section{Results And Discussion}

\subsection{FTIR Analysis}

The FTIR spectra of FeS NP and FeS/chitosan-g-poly(acrylamide) nanocomposite are shown in Fig. 1 (A, B). Figure $1 \mathrm{~A}$ showed a wide peak at $3332 \mathrm{~cm}^{-1}$ attributed to $\mathrm{O}-\mathrm{H}$ vibrations from water molecules absorbed by the sample. Peaks at $1632 \mathrm{~cm}^{-1}$ and $621 \mathrm{~cm}^{-1}$ were as a result of S-S vibrational stretch from the FeS nanoparticle [28]. A peak at $1133 \mathrm{~cm}^{-1}$ was characteristic of the S-O stretching vibration. In the fingerprint region, vibration bands corresponding to Fe-S stretch were observed below $500 \mathrm{~cm}^{-1}$ [29]. The FTIR of the grafted nanocomposite (Fig. 1B) showed a broad absorption band at $3188 \mathrm{~cm}^{-1}$ which was due to $\mathrm{N}-\mathrm{H}$ vibrations of amide groups and $\mathrm{O}-\mathrm{H}$ stretching of chitosan coinciding. A band at $1543 \mathrm{~cm}^{-1}$ was ascribed to the $(C=0)$ vibrations of secondary amide [30,31]. A band at $1401 \mathrm{~cm}^{-1}$ was due to $\mathrm{C}-\mathrm{N}$ vibrational stretch which was an indication of the grafting between chitosan and polyacrylamide [30]. Peaks found below $500 \mathrm{~cm}^{-1}$ were as a result of Fe-S stretching mode [22, 29]. The shift in peak positions of Fe-S bands indicated the interaction of the copolymer with the nanocomposite.

\subsection{XRD Analysis}


Fig 2 shows the XRD patterns of the as-synthesized FeS NP and FeS/chitosan-g- poly(acrylamide) nanocomposite. The peak positions ( $2 \theta$ values) at $17.56 \rrbracket, 28.83 \rrbracket$ and $40.75 \rrbracket$ corresponded to reflections from the (001), (101) and (111) planes of the tetragonal FeS phase (JCPDS: 86-0389) [29]. The grafted nanocomposite showed lower intensity in the peaks as compared to the FeS NP. This may be due to the interaction of the polymers (chitosan and polyacrylamide) with the nanoparticle and the less crystalline nature of the nanocomposite, compared to the nanoparticle [31]. From the Sherrer equation, the crystallite size of the FeS nanoparticle was found to be $6.2 \mathrm{~nm}$.

\subsection{SEM and TEM analysis}

(Fig. 3A, B) shows the SEM and TEM micrographs of the as-synthesized FeS nanoparticle. The assynthesized FeS nanoparticles were seen to be agglomerated and spherical or globular shaped. FeS NP synthesized through conventional methods, tend to agglomerate rapidly to macroparticles due to the interparticle van der Waals interaction [32]. Similar spherical shaped results were reported by other researchers [28, 33-35]. Figure 3C, D shows SEM image of FeS/chitosan-g-poly(acrylamide). nanocomposite and the SAED pattern of FeS NP obtained from the TEM microscope respectively. The SEM of the graft nanocomposite revealed that FeS NP was coated by the copolymer. The flake-like appearance was due to the grafting of FeS and polymers (chitosan and acrylamide) [31]. Though not all of the chitosan and acrylamide were fully grafted.

The SAED pattern of FeS (Fig. 3D) showed small spots forming rings ascribed to the Bragg reflections from the individual crystallite of the FeS nanoparticle indicating polycrystalline nature of the particles [36].

\subsection{Adsorption Removal Experiments}

\subsubsection{Effect of EY concentration, FeS/chitosan-g-poly(acrylamide) dosage and contact time}

From the graph (Fig. 4A), the removal efficiency decreased from 92.32-86.56\% with an increase in EY concentration. However, the amount of dye adsorbed per unit mass of the adsorbent increased from $55.39 \mathrm{mg} \mathrm{g}^{-1}$ to $129.84 \mathrm{mg} \mathrm{g}^{-1}$ with an increase in EY concentration. The decrease in R.E may be due to the fewer number of available surface-active sites as the concentration increased. The increase in Qe may be ascribed to a huge driving force of the EY particles. At lower concentrations, fewer adsorbate particles are attached to the surface of the FeS/chitosan-g-poly(acrylamide) nanocomposite but as the concentration increased, the mass transfer driving force towards the adsorbent surface increased.

Fig 4B shows the effect of adsorbent dose on the adsorption of EY onto FeS/chitosan-gpoly(acrylamide) nanocomposite by varying the dosage in $50 \mathrm{ml}$ of the dye solution. The removal 
a decreasing manner. The initial increase may be ascribed to the availability of adsorption sites and the plateau and eventual decrease may be a result of saturation of the adsorption sites. However, $\mathrm{Q}_{\mathrm{e}}$ reduced from $78.16 \mathrm{mg} \mathrm{g}^{-1}$ to $11.48 \mathrm{mg} \mathrm{g}^{-1}$ with an increase in FeS/chitosan-g- poly(acrylamide) dose. This may be as a result of the adsorbent surface sites available to EY overlapping. However, any additional increase in FeS/chitosan-g- poly(acrylamide) dosage had little effect on the adsorption.

The overall trend for both R.E and Qe was the same in Fig. 4C. There was a rapid rise in adsorption between the first 10 to 30 minutes after which there was a gradual rise. The rapid rise in the first 30 minutes may be due to the availability of more vacant adsorption sites.

\subsubsection{Effect of Temperature and $\mathrm{pH}$}

The decrease in Qe and R.E (Fig. 5A) with rising temperature indicate that the adsorption was an exothermic process. This may be due to a decrease in adsorptive forces between the adsorbate and the adsorbent as the temperature increased.

The amount of dye uptake per unit mass and removal efficiency of EY were strongly affected by the pH of the wastewater as shown in Fig. 5B. Qe and R.E increased gradually. This may suggest that there was a higher affinity between the adsorbate and the nanocomposite at higher $\mathrm{pH}$.

\subsection{Adsorption Isotherms}

To be able to efficiently utilize the adsorption system for practical applications, the Langmuir, Freundlich and the Dubinin-Radushkevich isotherms were employed in this work.

Figure 6 below shows the isotherm equilibrium data points for adsorption of EY onto FeS/chitosan-gpoly(acrylamide) nanocomposite.

From the graphs, the $\mathrm{R}^{2}$ value of the Langmuir isotherm was 0.9591 , Freundlich isotherm was 0.9657 and that of Dubinin-Radushkevich was 0.8243 . It can be concluded that Freundlich isotherm fitted the system since the $R^{2}$ value was high.

The mean free energy of adsorption, $E$, was computed to be $0.408 \mathrm{~kJ} \mathrm{~mol}^{-1}$ which was within the range of $0<\mathrm{E}<8 \mathrm{~kJ} \mathrm{~mol}^{-1}$ thus the adsorption was physical.

\subsection{Adsorption Kinetics and Thermodynamic studies}

To ascertain which kinetic order explains the adsorption of Eosin yellow onto FeS - chitosan-gacrylamide composite, the contact time studies were evaluated using the pseudo-first order and the pseudo-second-order kinetics. The best fit results were obtained in the pseudo-second-order model with Loading [MathJax]/jax/output/CommonHTML/jax.js 
an $R^{2}$ value (0.9997) closer to unity as compared to the pseudo-first order $R^{2}$ value of 0.9673 . Hence, it was established that the adsorption followed a pseudo-second-order process. A similar trend on the adsorption of Eosin $Y$ was also reported $[6,37]$.

Table 1 below summarizes the thermodynamic studies of the adsorption process

Table 1

Thermodynamic parameters for EY adsorption onto FeS/chitosan-g-poly(acrylamide) nanocomposite

\begin{tabular}{|c|c|c|c|c|c|c|}
\hline$\Delta \mathrm{H}^{\circ}\left(\mathrm{kJ} \mathrm{mol}^{-1}\right)$ & $\Delta \mathrm{S}^{\circ}\left(\mathrm{kJ} \mathrm{mol}^{-1}\right)$ & $\Delta \mathrm{G}^{\circ}\left(\mathrm{kJ} \mathrm{mol}^{-1} \cdot \mathrm{K}\right)$ & & & & \\
\hline & & $300 \mathrm{~K}$ & $303 \mathrm{~K}$ & $308 \mathrm{~K}$ & $313 \mathrm{~K}$ & $318 \mathrm{~K}$ \\
\hline-12.243 & -0.023 & -5.492 & -5.252 & -5.152 & -5.005 & -5.078 \\
\hline
\end{tabular}

The negative $\Delta \mathrm{H}^{\circ}$ value indicated an exothermic process which correlates to the adsorption studies on the impact of temperature on the adsorption process. The negative value of $\Delta S^{0}$ showed reduced randomness during the adsorption process. It also suggests that there was no substantial change going taking place in the internal structures of FeS/chitosan-g-poly(acrylamide) composite during the adsorption process [38]. The negative values of $\Delta \mathrm{G}^{\circ}$ suggested the spontaneity of the adsorption process.

\section{Conclusion}

FeS and FeS/chitosan-g-acrylamide nanomaterials were successfully synthesized by co-precipitation and microwave-assisted grafting respectively. The XRD spectra confirmed the tetragonal phase of FeS and particle size within the nanometer range. The FTIR confirmed the formation of FeS and its associated nanocomposite. SEM and TEM confirmed the morphology of the nanoparticle as well as the grafting of the polymers (chitosan and acrylamide). The SAED pattern indicated the polycrystalline nature of the nanoparticle. Batch adsorption studies revealed the dependency of the nanomaterial on adsorbent dosage, $\mathrm{pH}$, temperature, contact time and adsorbate concentration. The Freundlich isotherm model fitted the adsorption process. This is an indication of heterogeneous adsorption. The thermodynamic parameters according to the $\Delta \mathrm{G}^{\circ}$ showed a spontaneous and thermodynamically stable process, the $\Delta \mathrm{S}^{\circ}$ indicated a reduced disorderliness in the adsorption process and the $\Delta \mathrm{H}^{\circ}$ depicted an exothermic adsorption process. The FeS/chitosan-g-acrylamide, therefore, showed potential use as an adsorbent for the removal of organic dyes (Eosin Y) from wastewater.

\section{Declarations}

\section{Availability of data and materials}

Not applicable

Loading [MathJax]/jax/output/CommonHTML/jax.js

Page 10/20 


\section{Competing interests}

The authors declare they have no competing interests.

\section{Funding}

Not applicable

\section{Authors' contributions}

Eric S. Agorku: Conceptualization, Methodology, Validation, Formal analysis, Investigation, Resources, Writing - Review \& Editing, Visualization, Supervision, Project administration.

Bernice Y. Danu: Methodology, Validation, Investigation, Formal analysis, Writing - Original Draft, Visualization

Francis K. Ampong: Writing - Review \& Editing, Supervision.

Johannes A.M. Awudza: Writing - Review \& Editing.

Vincent Torve: Writing - Review \& Editing.

Caleb Amponsah: Investigation.

Ruth N.M Quaye: Investigation.

Onoyivwe M. Ama: Writing - Review \& Editing, Resources.

Peter 0. Osifo: Resources.

Suprakas S. Ray: Writing - Review \& Editing, Resources.

\section{Acknowledgements}

The authors acknowledge the technical support from DST-CSIR National Center for Nanostructured Materials, CSIR in the characterization of the materials. The authors also thank the support of the Royal Society- Department for International Development (DFID) Africa Capacity Building Initiative (ACBI), UK, towards this work.

\section{References}


2. Pokhrel D, Viraraghavan T. Treatment of pulp and paper mill wastewater - A review. Sci Total Environ. 2004; 333:37-58

3. Mahmoodi MN, Arami M. Modeling and Sensitivity Analysis of Dyes Adsorption onto Natural Adsorbent from Colored Textile Wastewater Niyaz. J Appl Polym Sci. 2008; 109:4043-4048

4. Mahmoodi NM, Salehi R, Arami M, Bahrami H. Dye removal from colored textile wastewater using chitosan in binary systems. Desalination. 2011; 267:64-72

5. Mahmoodi NM, Arami M. Degradation and toxicity reduction of textile wastewater using immobilized titania nanophotocatalysis. J Photochem Photobiol B Biol. 2009; 94:20-24

6. Subramani S, Thinakaran N. Isotherm, kinetic and thermodynamic studies on the adsorption behaviour of textile dyes onto chitosan. Process Saf Environ Prot. 2017; 106:1-10

7. Chatterjee S, Chatterjee S, Chatterjee BP, Das AR. Adsorption of a model anionic dye, eosin $Y$, from aqueous solution by chitosan hydrobeads. J ofColloid Interface Sci. 2005;288:30-35

8. Gupta K, Bhattacharya S, Chattopadhyay D, Mukhopadhyay A, Biswas H, Dutta J, Ray NR, Ghosh UC. Ceria associated manganese oxide nanoparticles: Synthesis, characterization and arsenic(V) sorption behavior. Chem Eng J. 2011; 172:219-229

9. Aksu Z. Application of biosorption for the removal of organic pollutants: A review. Process Biochem. 2005; 40:997-1026

10. Fosso-Kankeu E, Mittal H, Mishra SB, Mishra AK. Gum ghatti and acrylic acid based biodegradable hydrogels for the effective adsorption of cationic dyes. J Ind Eng Chem. 2015; 22:171-178

11. Sánchez-Martín J, Beltrán-Heredia J, Gragera-Carvajal J. Caesalpinia spinosa and Castanea sativa tannins: A new source of biopolymers with adsorbent capacity. Preliminary assessment on cationic dye removal. Ind Crops Prod. 2011; 34:1238-1240

12. Zhang Z, O'Hara IM, Kent GA, Doherty WOS. Comparative study on adsorption of two cationic dyes by milled sugarcane bagasse. Ind Crops Prod. 2013; 42:41-49

13. Jeon YS, Lei J, Kim JH. Dye adsorption characteristics of alginate/polyaspartate hydrogels. $\mathrm{J}$ Ind Eng Chem. 2008; 14:726-731

14. Mittal $\mathrm{H}$, Mishra SB. Gum ghatti and $\mathrm{Fe}_{3} \mathrm{O}_{4}$ magnetic nanoparticles based nanocomposites for the effective adsorption of rhodamine B. Carbohydr Polym. 2014; 101:1255-1264

15. Zhou YT, Nie HL, Branford-White C, He ZY, Zhu LM. Removal of $\mathrm{Cu}^{2+}$ from aqueous solution by chitosan-coated magnetic nanoparticles modified with a-ketoglutaric acid. J Colloid Interface Sci. 2009; 330:29-37

16. Mittal H, Ray SS. A study on the adsorption of methylene blue onto gum ghatti/ $/ \mathrm{TiO}_{2}$ nanoparticlesbased hydrogel nanocomposite. Int J Biol Macromol. 2016; 88:66-80

17. Xu YY, Zhou M, Geng HJ, Hao JJ, Ou QQ, Qi S Da, Chen HL, Chen XG. A simplified method for synthesis of $\mathrm{Fe}_{3} \mathrm{O}_{4} @ P A A$ nanoparticles and its application for the removal of basic dyes. Appl Surf Sci. 2012; 258:3897-3902 
18. Shukla SK, Mishra AK, Arotiba OA, Mamba BB. Chitosan-based nanomaterials: A state-of-the-art review. Int J Biol Macromol. 2013; 1-13

19. Shigehiro H, Haruyoshi S, Yasutoshi A, Isao N. Chitosan: a biocompatible material for oral and intravenous administrations. Prog Biomed Polym. 1990; 283-290

20. Pillai CKS, Paul W, Sharma CP. Chitin and chitosan polymers: Chemistry, solubility and fiber formation. Prog Polym Sci. 2009; 34:641-678

21. Park D, Yun YS, Park JM. The past, present, and future trends of biosorption. Biotechnol Bioprocess Eng. 2010; 15:86-102

22. Gupta D, Singh D, Kothiyal NC, Saini AK, Singh VP, Pathania D. Synthesis of chitosan-gpoly(acrylamide)/ZnS nanocomposite for controlled drug delivery and antimicrobial activity. Int $J$ Biol Macromol. 2015; 74:547-557

23. Langmuir I. The constitution and fundamental properties of solids and liquids. Part II.-Liquids. J Franklin Inst. 1917; 184:721

24. Dada A, Olalekan A, Olatunya A, Dada O. Langmuir, Freundlich, Temkin and Dubinin-Radushkevich Isotherms Studies of Equilibrium Sorption of $\mathrm{Zn}{ }^{2+}$ Unto Phosphoric Acid Modified Rice Husk. IOSR J Appl Chem. 2012; 3:38-45

25. Chen X. Modeling of Experimental Adsorption Isotherm Data. 2015; 14-22

26. Dubinin MM. THE POTENTIAL THEORY OF ADSORPTION OF GASES AND VAPORS. Expert of Gas Adsorption Analyzer Manufacturing Gold APP Instrument Expert of Gas Adsorption Analyzer Manufacturing. Theory Adsorpt. Gases Vap. 1959.

27. Dubinin MM. Fundamentals of the theory of adsorption in micropores of carbon adsorbents: Characteristics of their adsorption properties and microporous structures. Carbon N Y. 1989; 27:457467

28. Kaur G, Singh B, Singh P, Singh K, Thakur A, Kumar M, Bala R, Kumar A. Iron disulfide $\left(\mathrm{FeS}_{2}\right)$ : A promising material for removal of industrial pollutants. ChemistrySelect. 2017; 2:2166-2173

29. Malek TJ, Chaki SH, Deshpande MP. Structural, morphological, optical, thermal and magnetic study of mackinawite FeS nanoparticles synthesized by wet chemical reduction technique. Phys $B$ Condens Matter. 2018; 546:59-66

30. Ali Z, Venkatesan J, Kim S, Sudha P. Beneficial effect of chitosan-g-polyacrylamide copolymer in removal of heavy metals from industrial dye effluents. Int J Environ Sci. 2011; 1:820-833

31. Pathania D, Gupta D, Al-Muhtaseb AH, Sharma G, Kumar A, Naushad M, Ahamad T, Alshehri SM. Photocatalytic degradation of highly toxic dyes using chitosan-g-poly(acrylamide)/ZnS in presence of solar irradiation. J Photochem Photobiol A Chem. 2016; 329:61-68

32. Gong Y, Liu Y, Xiong Z, Kaback D, Zhao D. Immobilization of mercury in field soil and sediment using carboxymethyl cellulose stabilized iron sulfide nanoparticles. Nanotechnology. 2012; https://doi.org/10.1088/0957-4484/23/29/294007 
33. Kim EJ, Kim JH, Azad AM, Chang YS. Facile synthesis and characterization of Fe/FeS nanoparticles for environmental applications. ACS Appl Mater Interfaces. 2011; 3:1457-1462

34. Pethkar A V., Bhagat AP. Biopolymer stabilized iron sulphide nanoparticles for removal of acid black 1 dye. Mater Sci Forum. 2013; 757:285-293

35. Gartman A, Findlay AJ, Luther GW. Nanoparticulate pyrite and other nanoparticles are a widespread component of hydrothermal vent black smoker emissions. Chem Geol. 2014; 366:32-41

36. Paca AM, Ajibade PA. Synthesis, optical, and structural studies of iron sulphide nanoparticles and iron sulphide hydroxyethyl cellulose nanocomposites from bis-(Dithiocarbamato)iron(II) singlesource precursors. Nanomaterials. 2018; https://doi.org/10.3390/nano8040187

37. Mittal A, Jhare D, Mittal J. Adsorption of hazardous dye Eosin Yellow from aqueous solution onto waste material De-oiled Soya: Isotherm, kinetics and bulk removal. J Mol Liq. 2013; 179:133-140

38. Saha P, Chowdhury S. Insight Into Adsorption Thermodynamics. Thermodynamics. 2011; https://doi.org/10.5772/13474

\section{Figures}




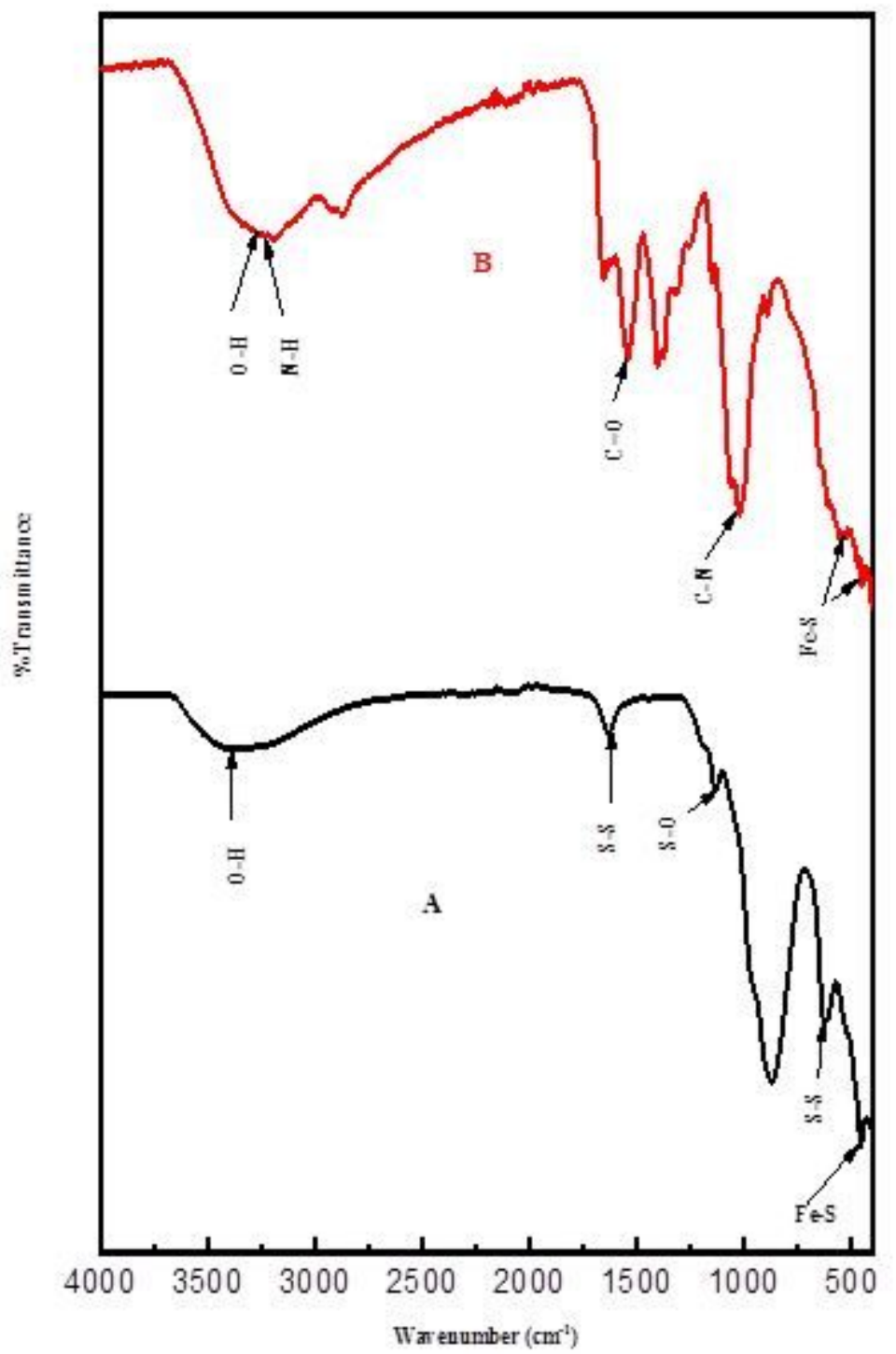

Figure 1

FTIR spectra of FeS NP (A) and FeS/chitosan-g-poly(acrylamide) nanocomposite (B). 


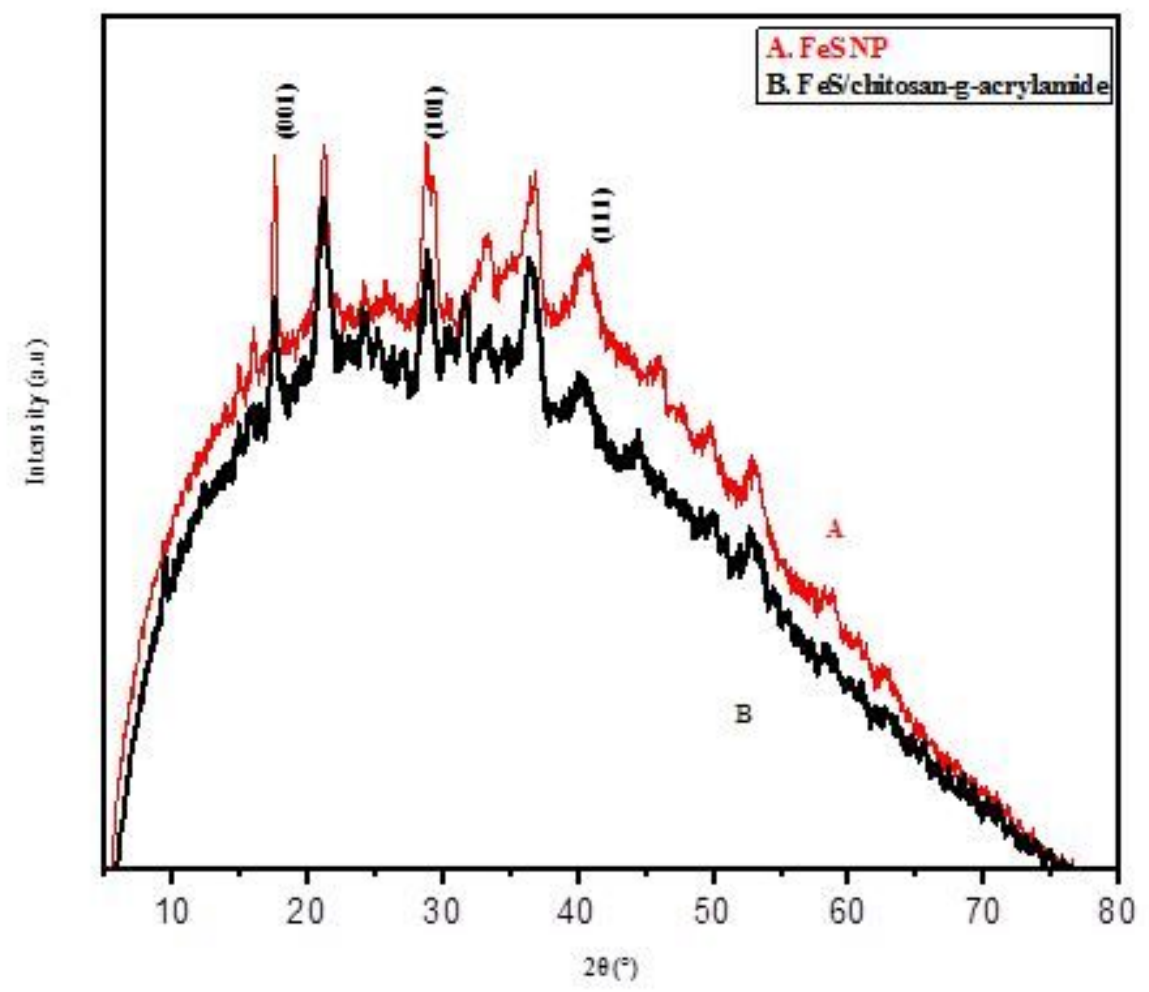

Figure 2

XRD patterns of FeS NP (A) and FeS/chitosan-g-poly(acrylamide) nanocomposite (B). 

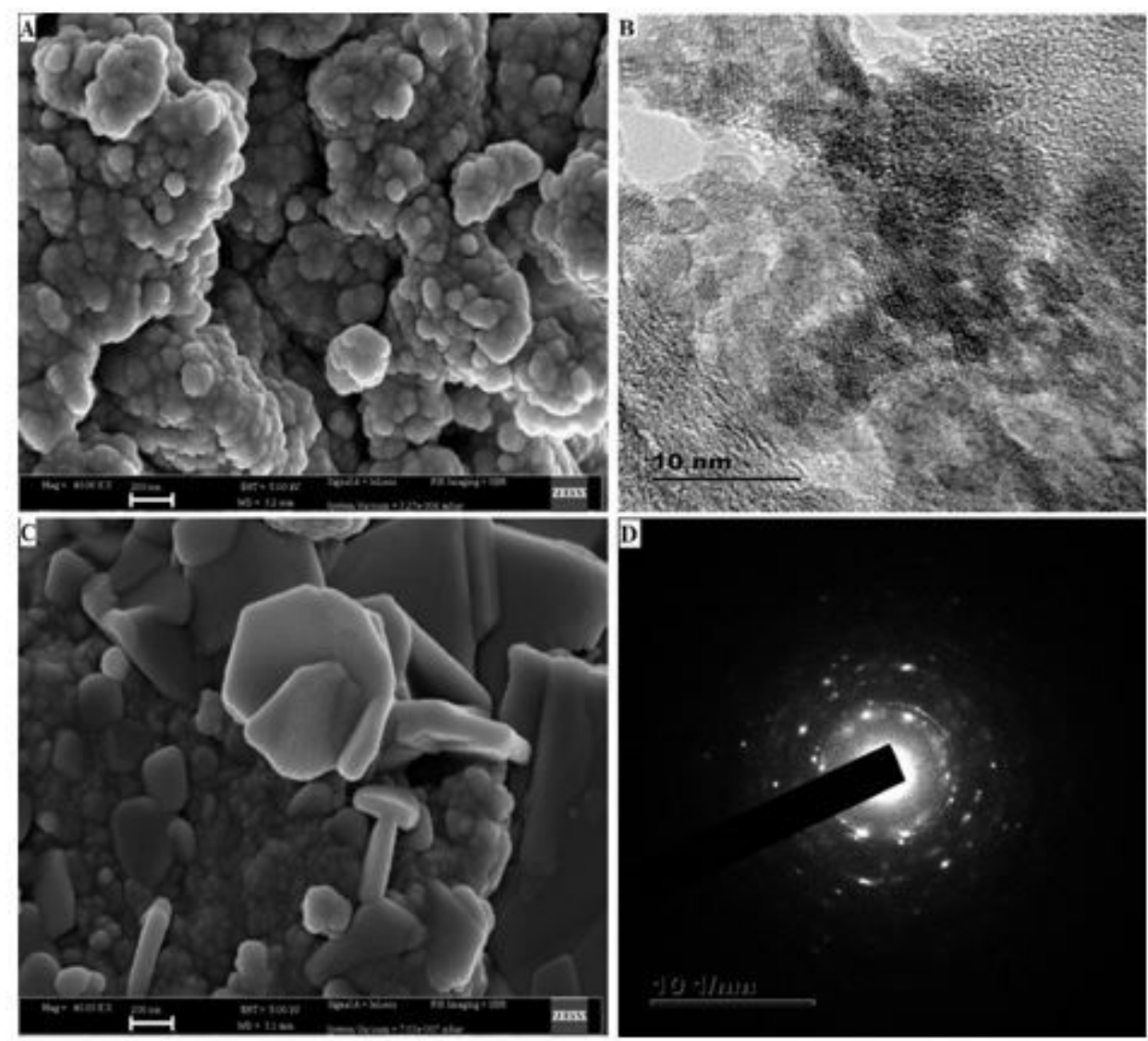

\section{Figure 3}

SEM image of FeS NP (A), TEM image of FeS NP (B), SEM image of FeS/chitosan-g-poly(acrylamide) nanocomposite (C), SAED pattern of FeS NP (D). 


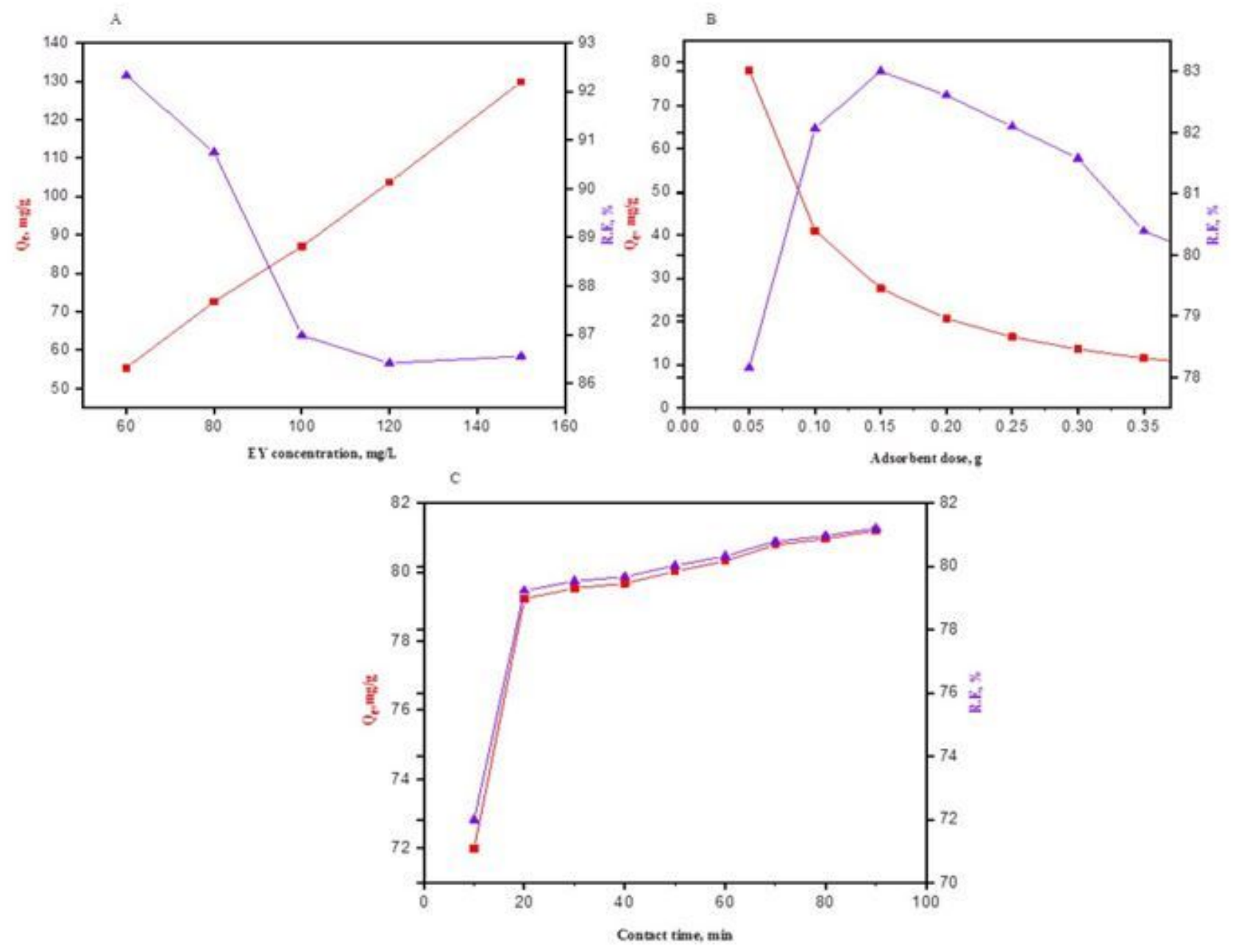

Figure 4

Effect of concentration (A), dosage (B) and contact time (C) on EY adsorption onto FeS/chitosan-gpoly(acrylamide) nanocomposite. Conditions: (A. temperature: $300 \mathrm{~K}$; time: 120 minutes; dose; 0.05 g/50 $\mathrm{ml}$ ) (B. temperature: $300 \mathrm{~K}$; Time: 120 minutes; concentration: $100 \mathrm{mg} \mathrm{L-1}$ ) (C. concentration: $100 \mathrm{mg} \mathrm{L-1}$; dose; $0.05 \mathrm{~g} / 50 \mathrm{ml}$; temperature: $300 \mathrm{~K}$ ). 

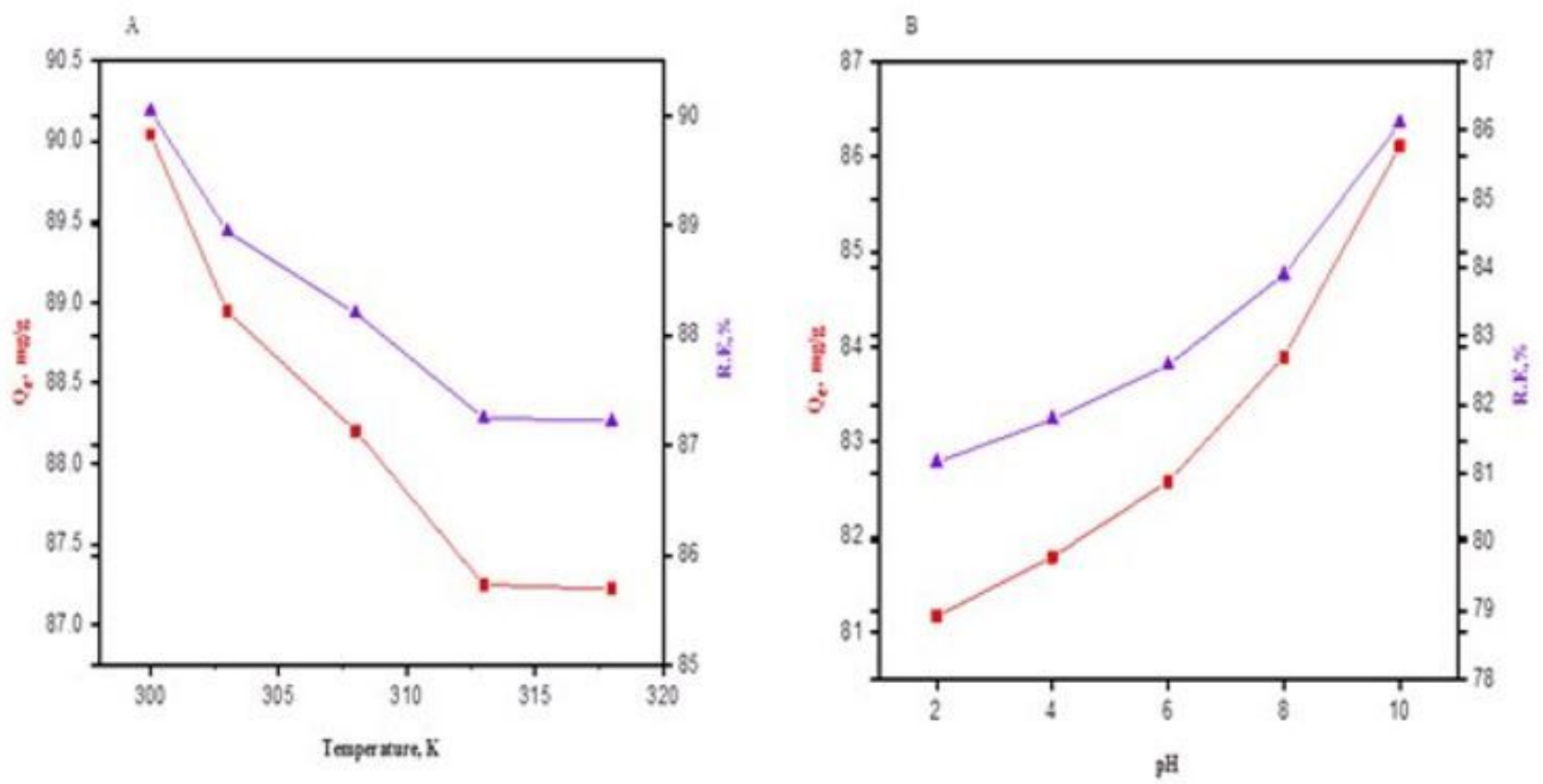

Figure 5

Effect of temperature (A) and $\mathrm{pH}(\mathrm{B})$ on EY adsorption onto FeS/chitosan-g-poly(acrylamide) nanocomposite. Conditions: (A. concentration: $100 \mathrm{mg} \mathrm{L-1;} \mathrm{time:} 30$ minutes; dose; $0.05 \mathrm{~g} / 50 \mathrm{ml}$ ) (B. temperature: $300 \mathrm{~K}$; Time: 120 minutes; concentration: 100 mg L-1). 

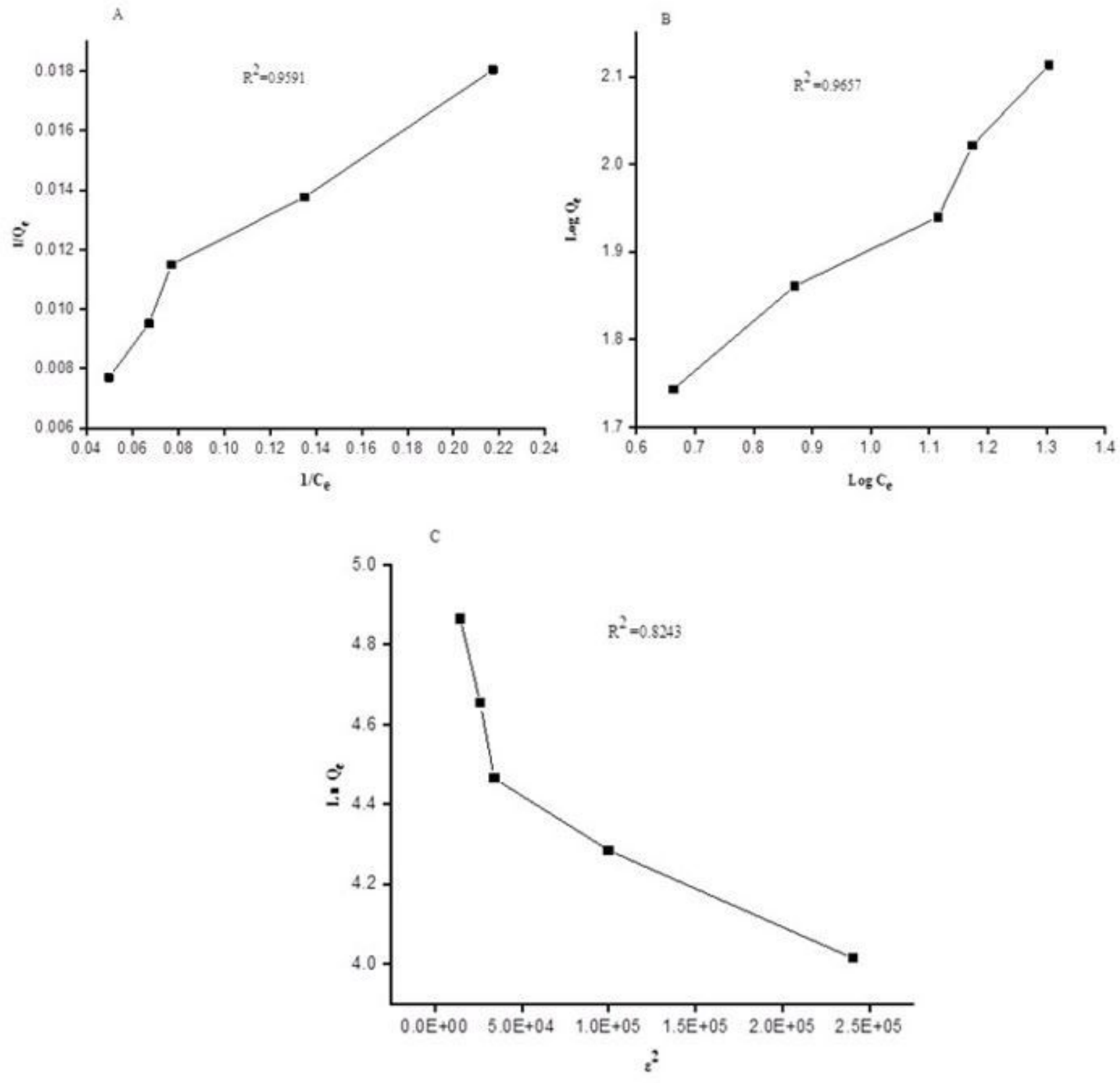

Figure 6

Langmuir (A), Freundlich (B) and Dubinin-Radushkevich (C) plots of EY adsorption onto FeS/chitosan-gpoly(acrylamide) nanocomposite. 